\title{
触 New Disease Reports \\ First report of Potato spindle tuber viroid in vegetatively propagated plants of Capsicum annuum in The Netherlands
}

\author{
J.Th.J. Verhoeven*, J.G.B. Voogd, N. Strik and J.W. Roenhorst
}

National Plant Protection Organization, P.O. Box 9102, HC Wageningen, The Netherlands

*E-mail: j.t.j.verhoeven@nvwa.nl

Received: 04 May 2016. Published: 16 Sep 2016.

Over recent decades Potato spindle tuber viroid (PSTVd, genus Pospiviroid) has been found in increasingly various crops. It may cause severe diseases in potato and tomato crops but usually occurs as symptomless infections in ornamental species (Verhoeven et al., 2010). Pepper (Capsicum апnиит) has been reported to show mild symptoms (Lebas et al., 2005). In 2016 a breeding company informed the National Plant Protection Organization (NPPO) of the Netherlands on the suspicion of PSTVd infections in four seedless pepper selections that had been propagated vegetatively. The suspected plants had been produced by a Dutch nursery that had imported the planting material from Israel. In the Netherlands, the plants were grown at four locations: two greenhouses of the same nursery at two locations (598 plants), a greenhouse for fruit production (1,616 plants) and another for demonstration purposes (100 plants) (EPPO, 2016). Within the four locations, plant age varied from young plants that had just been grafted to plants starting fruit production. In none of the pepper plants were any symptoms observed.

At all four locations the NPPO confirmed the presence of PSTVd in all pepper selections by RT-PCR according to Shamloul et al. (1997) and subsequent sequencing of the PCR products. The predominant sequence (GenBank Accession No. KX370618), detected in fourteen out of fifteen sequences was identical to FM998548, a sequence of an isolate from $S$. jasminoides, and one sequence showed minor differences. Based on these results, it is assumed that PSTVd-infected plants of $S$. jasminoides were the source of infection in the pepper plants. Aligning the sequence FM998548 with the predominant sequences of isolates from Brugmansia spp. and $S$. jasminoides, B1 and S1, respectively (Verhoeven et al., 2010), showed deviations at seven nucleotide positions of which four are identical to B1 and three to S1 (Fig. 1). Since these deviations only occurred at positions where the sequences of S1 and B1 differ, the sequence FM998548 could have resulted from a single recombination event in the terminal right and variable domains (Keese \& Symons, 1985) in a plant of S. jasminoides infected by both B1 and S1. The same deviations have also been found in an isolate from related pepper selections in Israel, indicating that infected planting material may have served as the pathway for introduction of PSTVd in peppers into The Netherlands.

At the nursery site PSTVd was also found in five out of twelve other vegetatively propagated pepper selections. Testing of potentially infected deliveries from this nursery revealed only one additional finding at a fruit production location. All infected plants were destroyed under official control of the NPPO. In addition, the national authorities of five other EU member states were informed on the delivery of infected pepper selections to growers in their countries.

The findings of PSTVd in vegetatively propagated selections of $C$. annuиm show that new propagation strategies of crops may result in additional risks for spreading pathogens such as viroids. Moreover, this outbreak again demonstrates the role of symptomlessly infected hosts in the epidemiology of pospiviroids. It is important that both plant health officers and policy makers are aware of the presence of these potential risks.

\section{References}

EPPO, 2016. Update on the situation of Potato spindle tuber viroid in the Netherlands. EPPO Reporting Service 4, 2016/083.

Keese P, Symons RH, 1985. Domains in viroids: evidence of intermolecular RNA rearrangements and their contribution to viroid evolution. Proceedings of the National Academy of Science of the United States of America 82, 4582-4586.

http://dx.doi.org/10.1073/pnas.82.14.4582

Lebas BSM, Clover GRG, Ochoa-Corona FM, Elliott DR, Tang Z, Alexander BJR, 2005. Distribution of Potato spindle tuber viroid in New Zealand glasshouse crops of capsicum and tomato. Australasian Plant Pathology 34, 129-133. http://dx.doi.org/10.1071/AP05002

Shamloul AM, Hadidi A, Zhu SF, Singh RP, Sagredo B, 1997. Sensitive detection of potato spindle tuber viroid using RT-PCR and identification of a viroid variant naturally infecting pepino plants. Canadian Journal of Plant Pathology 19, 89-96. http://dx.doi.org/10.1080/07060669709500580

Verhoeven JThJ, Jansen CCC, Botermans M, Roenhorst JW, 2010. Epidemiological evidence that vegetatively propagated, solanaceous plant species act as sources of Potato spindle tuber viroid inoculum for tomato. Plant Pathology 59, 3-12.

http://dx.doi.org/10.1111/j.1365-3059.2009.02173.x

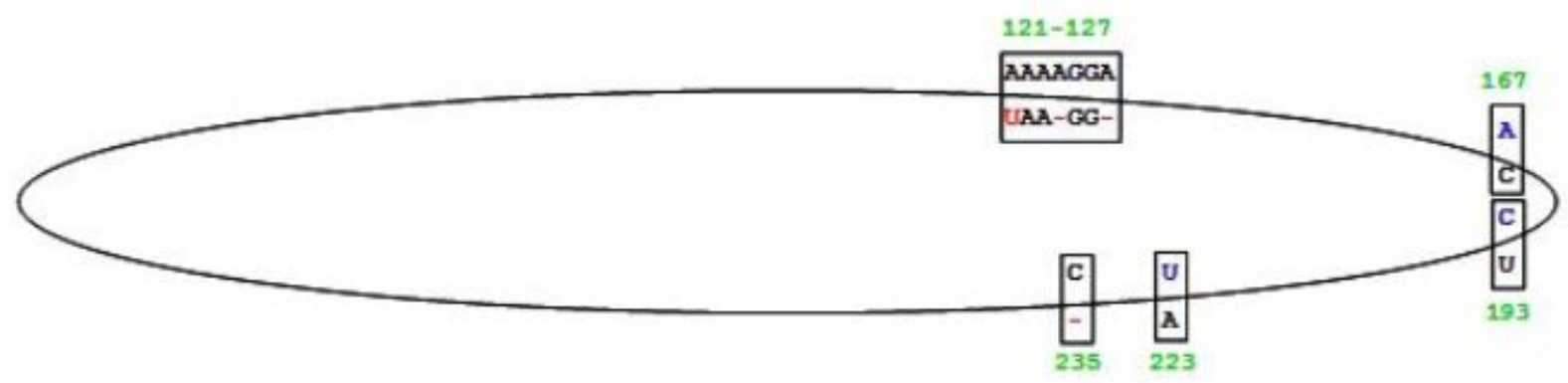

Figure 1

To cite this report: Verhoeven JTJ, Voogd JGB, Strik N, Roenhorst JW, 2016. First report of Potato spindle tuber viroid in vegetatively propagated plants of Capsicum annuum in The Netherlands. New Disease Reports 34, 12. http://dx.doi.org/10.5197/j.2044-0588.2016.034.012 